\title{
PERAGA FENOMENA KELISTRIKAN AKIBAT PERBEDAAN TEMPERTUR PADA PASANGAN KAWAT TEMBAGA DAN SENG
}

\author{
Kurnia Astari Pratama, Eko Suyanto, Wayan Suane \\ Program Studi Pendidikan Fisika, Universitas Lampung \\ Email: astari.pratama@gmail.com
}

Diterima: 24 Juli 2018. Disetujui: 8 Agustus 2018.

\begin{abstract}
Abstrak
Tujuan penelitian pengembangan ini adalah menghasilkan alat peraga fenomena kelistrikan yang berbasis lingkungan dan petunjuk penggunaannya (user manual) untuk pembelajaran fisika materi sumber energi listrik, mengetahui kelayakan dan spesifikasinya. Penelitian pengembangan ini menghasilkan produk alat peraga disertai user manual yang telah diuji spesifikasi dan kelayakannya. Berdasarkan uji yang telah dilakukan dapat diketahui bahwa; nilai koefisien seebeck pada pasangan kawat tunggal, seri, paralel berturut-turut sebesar $0,004 \mathrm{mV} /{ }^{0} \mathrm{C}, 0,064 \mathrm{mV} /{ }^{0} \mathrm{C}, 0,004 \mathrm{mV} /{ }^{0} \mathrm{C}$; volume wadah sisi dingin dan sisi panas konverter adalah 3,3 liter; suhu sisi dingin konverter adalah $0^{\circ} \mathrm{C}$; dan suhu sisi panas konverter berada pada rentang $30^{\circ} \mathrm{C}-90^{\circ} \mathrm{C}$. Hasil Uji kelayakan alat peraga fenomena kelistrikan dan user manual menyatakan bahwa produk layak untuk digunakan untuk mengamati perilaku perubahan panas menjadi listrik dengan skor 2,79 pada uji kelayakan fisik dan skor 3,11 pada uji ahli desain.
\end{abstract}

Kata Kunci: efek seebeck, energi listrik, energi panas, konversi energi.

\begin{abstract}
The purpose of this development research is produce props electrical-based phenomenon environment instructions for use (user manual) for physics learning material of electrical energy source,know the feasibility and specifications. This development research produces props product along with user manual that has been tested specification and feasibility.Based on the test that has been done can be seen that; coefficient value of seebeck on single, series, parallel, wire is consecutively equal to $0,004 \mathrm{mV}^{\rho} \mathrm{C}, 0,064$ $\mathrm{mV}^{\rho} \mathrm{C}, 0,004 \mathrm{mV}^{\rho} \mathrm{C}$; the volume of the cold side container and the hot side of the converter is 3.3 liters; the cold side temperature of the converter is $0^{\circ} \mathrm{C}$; and the heat side temperature of the converter is in the range $30^{\circ} \mathrm{C}-90^{\circ} \mathrm{C}$. Results of the feasibility test of electrical phenomenon props and user manual states that the product is suitable for use to observe the behavior of changing heat into electricity with a score of 2.79 on the physical fit and score of 3.11 on the design expert test.
\end{abstract}

Keywords: seebeck effect, electric energy, heat energy, energy conversion.

\section{PENDAHULUAN}

Siswa kurang bahkan tidak memahami materi pembelajaran fisika yang bersifat sukar dimungkinkan

karena faktor belajar siswa yang kurang efektif, bahkan siswa sendiri 
Pratama., Suyanto., Suane. - Peraga Fenomena Kelistrikan...

tidak merasa termotivasi di dalam mengikuti pembelajaran di kelas. Pembelajaran fisika untuk saat ini membosankan seperti yang dirasakan oleh kebanyakan siswa terutama jenjang SMA. Masih banyak pembelajaran fisika dilakukan dengan meminta siswa untuk menghafal rumus-rumus, dan mengerjakan soalsoal yang ada di dalam buku tanpa harus memahami konsep, fakta dan pengalaman empirik. Hal semacam ini yang membuat siswa kehilangan kesempatan untuk memperoleh pengalaman belajar secara empirik dan pembelajaran fisika menjadi kurang menarik.

Kecenderungan pembelajaran fisika yang kurang menarik merupakan hal wajar dialami oleh guru yang tidak memahami kebutuhan dari siswa. Fisika sebagai bagian dari IPA mengkaji perilaku, struktur dan interaksi benda secara empirik, oleh sebab itu dalam pembelajaran fisika seharusnya dimulai dengan pengamatan yang melibatkan fenomena dan gejala alam yang berkaitan dengan materi fisika yang akan diajarkan (Fatonah \& Prasetyo, 2014).
Berdasarkan tinjauan kurikulum tingkat SMA yang termuat di dalam silabus dan hasil analisis beberapa LKS serta buku siswa SMA kelas XII, tidak terdapat materi konversi energi yang lebih rinci mengenai konversi energi panas menjadi energi listrik.

Guru masih terkendala dalam mempresentasikan konversi energi panas menjadi energi listrik, sehingga siswa tidak memahami materi pembelajaran fisika tersebut. Materi konversi energi panas menjadi energi listrik jugasangat diperlukan dalam pembelajaran fisika. Hal ini diperlukan untuk memperkaya pengetahuan siswa tentang sumber energi listrik selain energi kimia, nuklir, dan matahari. Dengan memahami materi tersebut siswa mempunyai peluang yang lebih besar untuk mencari alternatif sumber energi listrik di dalam kehidupan mereka sehari-hari. Namun perangkat peraga konversi energi panas menjadi energi listrik masih sulit ditemukan dalam kehidupan sehari-hari.

Salah satu cara untuk mempelajari konversi energi adalah dengan menggunakan bahan termoelektrik. 
Pratama., Suyanto., Suane. - Peraga Fenomena Kelistrikan...

Teknologi termoelektrik dikenal sebagai cara dalam mengkonversi energi panas (perbedaan temperatur) menjadi energy listrik (generator termoelektrik) secara langsung, atau sebaliknya, dari listrik menghasilkan dingin (Sutjahja, 2011; Montecucco, Siviter, \& Knox, 2014)

Agar bisa menghasilkan listrik, material termoelektrik cukup diletakkan atau dipasang sedemikian rupa dalam rangkaian yang menghubungkan sumber panas dan dingin. Dari rangkaian tersebut akan dihasilkan sejumlah arus listrik sesuai dengan jenis bahan atau material yang digunakan (Ramdini, 2014). Keunggulan dari sistem termolektrik adalah kemampuan efisiensinya yang berada pada rentang maksimal 5\% (Pranita et al. 2015).

Putra (2009) menyatakan termoelektrik dipengaruhi oleh dua efek, yaitu efek seebeck dan efek peltier. Penelitian ini akan mengaplikasikan efek seebeck. Efek seebeck menjelaskan bahwa ada dua bahan berbeda yang kemudian kedua ujungnya disambungkan. Jika ada perbedaan temperatur pada kedua sambungan maka timbul arus listrik.
Ketika sambungan diputus kemudian disambungkan dengan sebuah galvanometer maka akan ada tegangan dari kedua ujung sambungan. Nilai tegangan yang dihasilkan tergantung pada perbedaan suhu dan koefisien Seebeck.

Berdasarkan percobaan, berbagai macam pasangan kawat logam digunakan dalam melakukan penelitian ini. Selain jenis logam yang dipakai, panjang, dan suhu pada masing-masing logam juga divariasikan.

Pada dasarnya alat yang dikembangkan mengikuti prinsip kerja termokopel. termokopel dibuat berdasarkan pada sifat-sifat termal logam. Jika sebuah batang logam dipanaskan pada salah satu ujungnya maka elektron-elektron pada ujung logam tersebut akan bergerak semakin aktif dan akan menempati ruang yang semakin luas, elektronelektron saling berdesakan dan bergerak ke arah ujung batang yang tidak dipanaskan. Dengan demikian pada ujung batang yang dipanaskan akan terjadi muatan positif dan yang tidak dipanaskan menjadi 
Pratama., Suyanto., Suane. - Peraga Fenomena Kelistrikan...

muatan negatif. Termokopel merupakan sensor yang mengubah perbedaan suhu menjadi perubahan tegangan, hal ini disebabkan oleh perbedaan kerapatan yang dimiliki oleh masing-masing logam yang bergantung pada massa jenis logam (Wendri, Supardi, Suarbawa, \& Yuliantini, 2012). Pada penelitian ini akan digunakan pasangan kawat tembaga $(\mathrm{Cu})$ dan seng $(\mathrm{Zn}$ karena pasangan kawat ini dapat menjelaskan gejala efek Seebeck secara empirik dan tidak menimbulkan korosi. Selain itu, dengan mempertimbangkan keteraturan kenaikan tegangan dan karakteristik sifat logam maka pasangan logam ini dipilih. Pada penelitian ini satu buah pasangan kawat telah menunjukkan fenomena kelistrikan berdasarkan konsep seebeck, yakni dengan adanya arus listrik yang mengalir pada pasangan kawat yang menghasilkan tegangan. Karena tegangan yang dihasilkan oleh satu pasangan kawat itu sangat kecil, maka peneliti mencoba untuk memperbesar tegangan dengan cara menyusun pasangan logam secara seri dan secara paralel.
Dalam penelitian ini diharapkan bisa menjadi solusi keterbatasan perangkat peragaan perubahan energi panas menjadi energi listrik yang dapat membantu siswa untuk mendalami perilaku perubahan energi panas menjadi energi listrik dengan menggunakan alat dan bahan yang tersedia di sekitar (berbasis lingkungan). Alat peraga ini dipresentasikan dengan menggunakan prinsip kerja efek seebeck. Penelitian ini bertujuan untuk mengembangkan peraga konversi energi panas menjadi energi listrik dengan konsep efek seebeck berbasis lingkungan dan mengetahui kinerja peraga tersebut.

Selain itu, penelitian ini juga bertujuan untuk mengetahui hubungan peningkatan jumlah besar tegangan yang dihasilkan jika pasangan kawat disusun secara seri dan paralel, oleh peraga konversi energi panas menjadi energi listrik dengan konsep efek seebeck berbasis lingkungan menggunakan pasangan kawat seng $(\mathrm{Zn})$ dan tembaga $(\mathrm{Cu})$.

\section{METODE}

Desain pengembangan ini menggunakan pendekatan penelitian 
Pratama., Suyanto., Suane. - Peraga Fenomena Kelistrikan...

pengembangan dengan beberapa tahapan yaitu,analisis kebutuhan, identifikasi sumber daya untuk memenuhi kebutuhan, identifikasi spesifikasi produk, pengembangan produk, uji produk, dan produksi.

Pada tahap pengembangan produk, pengembangan alat konversi energi panas menjadi energi listrik mengikuti tahapan dengan metode penelitian eksperimen. Tahapantahapan tersebut terdiri atas preparasi sampel dan pembuatan pasangan
Preparasi sampel dilakukan dengan mempersiapkan kawat berbagai jenis logam. Kawat logam tersebut dibersihkan dengan amplas agar permukaan bersih dari kotoran termasuk karat.

Pada tahap pembuatan pasangan logam, kawat logam yang telah disiapkan akan dipasangkan. Seperti ditunjukkan pada gambar 1, kawat logam yang telah disiapkan tersebut, selanjutnya digabungkan pada salah satu ujung logam dengan cara melilit. logam.

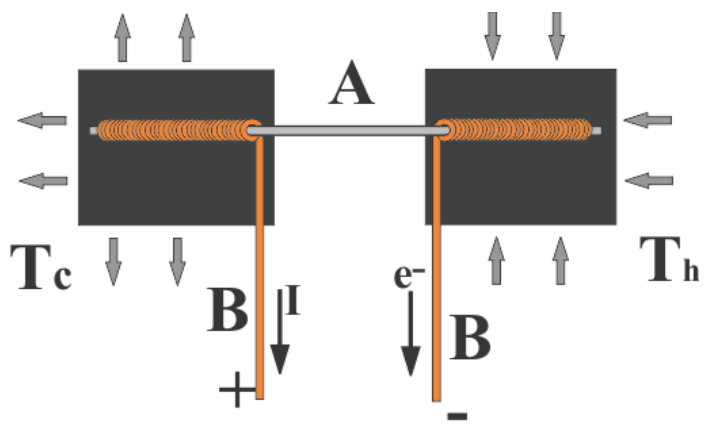

Gambar 1. Cara pembuatan pasangan kawat logam.

Pada pasangan-pasangan logam mempunyai titik pertemuan atau yang sering disebut lilitan. Titik pertemuan tersebut agar terhubung dengan sempurna perlu dibungkus atau dilapisi dengan silver glue paint dan carbon.

Pada penelitian ini terdapat beberapa variasi yang diharapkan selain untuk menampilakan fenomena konversi energi dari panas ke listrik, juga memperbesar tegangan dan arus yang dihasilkan sampel, dengan cara menserikan ataupun memparalelkan rangkaian pasangan kawat logam.

Penenentuan polaritas pada rangkaian seebeck, sambungan logam seperti pada gambar 1 di sebelah kanan dipanaskan (hoot) dan sambungan logam kiri didinginkan 
(cool). Pemanasan disebelah kanan menjadikan electron pada pita valensinya dapat berpindah ke pita konduksi baik di logam A ataupun logam B, karena jumlah elektron pada pita konduksi logam A lebih banyak dibandingkan elektron pada pita konduksi logam B, maka elektron pada pita konduksi logam A berdiusi ke pita konduksi logam B. Sehingga elektron bergerak ke bawah pada logam B (kanan) atau arus listrik bergerak pada logam B (kiri) ke bawah. Sedangkan pada logam A elektron bergerak dari kiri ke kanan dan arus listrik dengan arah sebaliknya. Berdasarkan penjelasan tersebut maka logam B di kanan disebut sebagai kutub negatip dan logam B di kiri disebut sebagai kutub positip.

Tahapan selanjutnya adalah Pengukuran $\mathrm{V}_{0}$ berdasarkan panjang kawat. Pada tahap ini dilakukan pengukuran pada sampel atau logam yang sudah dipasangkan. Skema dari proses percobaan pengukuran di atas seperti pada Gambar 2.

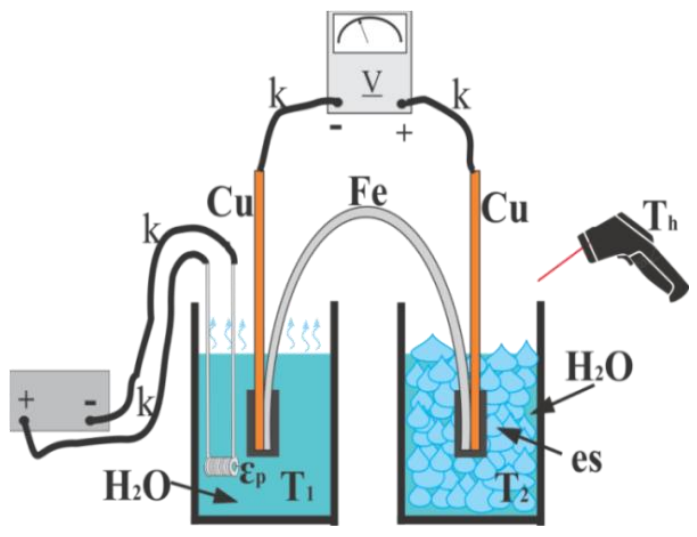

Gambar 2. Skema percobaan rangkaian seebeck

Ujung-ujung sampel berupa lilitan yang sudah dilapisi silver paint dan karbon tersebut celupkan masingmasing ke dalam dua jenis air, yaitu air panas dan es melebur. Setelah itu, ujung-ujung yang lain pada sampel dihubungkan atau diukur dengan multimeter digital.
Tahapan selanjutnya adalah mendesain rangkaian seri dan parallel. Pada bagian ini pasangan kawat disusun secara seri atau paralalel dengan tujuan untuk memperbesar tegangan yang dihasilkan. Desain rangkaian seri-paralel dapat dilihat pada Gambar 3 dan 4. 
Pratama., Suyanto., Suane. - Peraga Fenomena Kelistrikan...

Bagian akhir adalah tahapan desain ini dilakukan kalibrasi untuk menguji interface dari alat ini yang sensor temperatur dengan digambarkan pada gambar 5. Namun, menggunakan es untuk menetapkan sebelum dilakukan pengambilan data, titik bawah $0^{\circ} \mathrm{C}$ (Wendri, Supardi, sebagai langkah awal dari penelitian Suarbawa, \& Yuliantini, 2012).

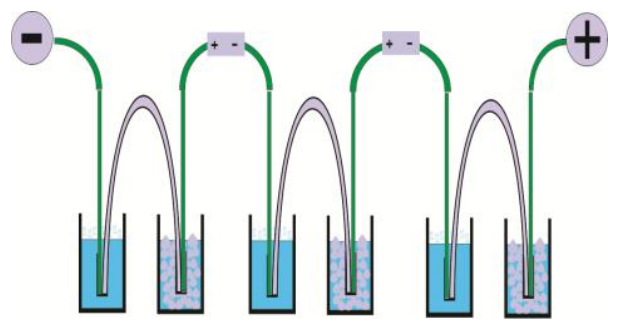

Gambar 3. Desain rangkaian seri

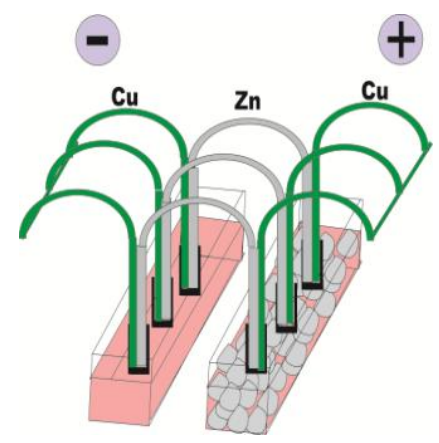

Gambar 4. Desain rangkaian paralel

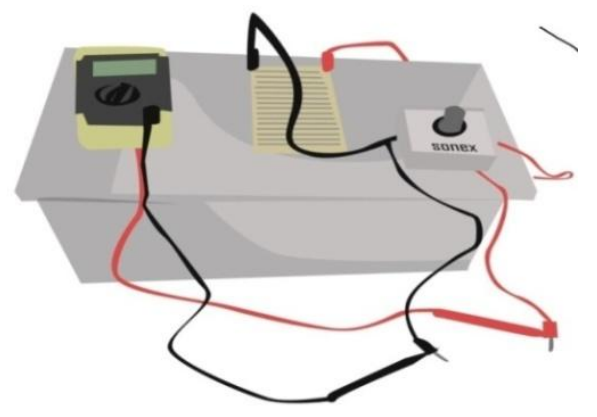

Gambar 5. Desain alat

\section{HASIL DAN PEMBAHASAN}

\section{Hasil}

Hasil utama dari pengembangan alat ini adalah berupa alat peraga penghasil energi listrik berbasis efek sebeeck yang dilengkapi dengan petunjuk penggunaan (user manual). Hasil dari setiap tahapan prosedur 
Pratama., Suyanto., Suane. - Peraga Fenomena Kelistrikan...

pengembangan yang dilakukan adalah analisis kebutuhan, identifikasi sumber daya, identifikasi spesifikasi produk, pengembangan produk, uji produk, produksi.

Data dalam percobaan pengukuran yang dilakukan dengan menggunakan alat peraga fenomena kelistrikan akibat perbedaan temperatur pada pasangan kawat tembaga dan seng. Hasil data pengukuran menggunakan empat belas pasang kawat tembaga dan seng dapat dilihat pada tabel 1 .

Tabel 1. Data hasil uji spesifikasi alat

\begin{tabular}{lllll}
\hline Percobaan ke & $\mathbf{V}_{(\text {Tegangan })}$ & \multicolumn{1}{c}{$\mathbf{T}_{(\text {Suhu })}$} & & $\mathbf{T . V}$ \\
& & & $\mathbf{T}^{2}$ \\
\hline 1 & 0,80 & 30 & 24 & 900 \\
2 & 4,03 & 35 & 141,17 & 1.225 \\
3 & 6,13 & 40 & 245,33 & 1.600 \\
4 & 9,60 & 45 & 432 & 2.025 \\
5 & 13,63 & 50 & 681,67 & 2.500 \\
6 & 16,80 & 55 & 924 & 3.025 \\
7 & 20,50 & 60 & 1230 & 3.600 \\
8 & 23,90 & 65 & 1553,50 & 4.225 \\
9 & 27,07 & 70 & 1894,67 & 4.900 \\
10 & 32,53 & 75 & 2440 & 5.625 \\
11 & 33,93 & 80 & 2714,67 & 6.400 \\
12 & 36,20 & 85 & 3077 & 7.225 \\
13 & 39,90 & 90 & 3591 & 8.100 \\
$\sum$ & 265,03 & 780 & 18949 & 51350 \\
$\mathrm{~N} \sum$ & 3445,43 & 10140 & 246337 & 667550 \\
\hline
\end{tabular}

Berdasarkan data yang diperoleh dari pengukuran menggunakan alat peraga fenomena kelistrikan menggunakan pasangan kawat tunggal. Untuk mengetahui hubungan antara peningkatan suhu dan tegangan didefinisikan dengan persamaan garis lurus $\mathrm{y}=0,042 \mathrm{x}-1,347$ dan $\mathrm{R}^{2}=$ 0,857 yaitu nilai koefisien determinasi adalah 0,857 . Nilai koefisien determinasi ini menunjukkan pengaruh temperatur terhadap tegangan yang dihasilkan alat peraga sebesar $0,86 \%$ yang berarti sangat berpengaruh. Pada pasangan kawat yang disusun secara seri diperoleh persamaan garis lurus $\mathrm{y}=0,669 \mathrm{x}-$ 19,79 dan $\mathrm{R}^{2}=0,996$ yaitu nilai koefisien determinasi adalah 0,996. Nilai koefisien determinasi seperti ditunjukkan pada gambar 6 menunjukkan pengaruh temperatur terhadap tegangan yang dihasilkan alat peraga sebesar $0,996 \%$ yang 
Pratama., Suyanto., Suane. - Peraga Fenomena Kelistrikan...

berarti sangat berpengaruh pada Nilai koefisien determinasi seperti pasangan kawat seri.

pada gambar 7 menunjukkan

Sedangkan pada pasangan kawat pengaruh temperatur terhadap yang disusun secara paralel diperoleh tegangan yang dihasilkan alat peraga persamaan garis lurus $\mathrm{y}=0,041 \mathrm{x}-\quad$ sebesar $0,83 \%$ yang berarti sangat 1,349 dan $\mathrm{R}^{2}=0,83$ yaitu nilai berpengaruh pada pasangan kawat koefisien determinasi adalah 0,83. paralel.

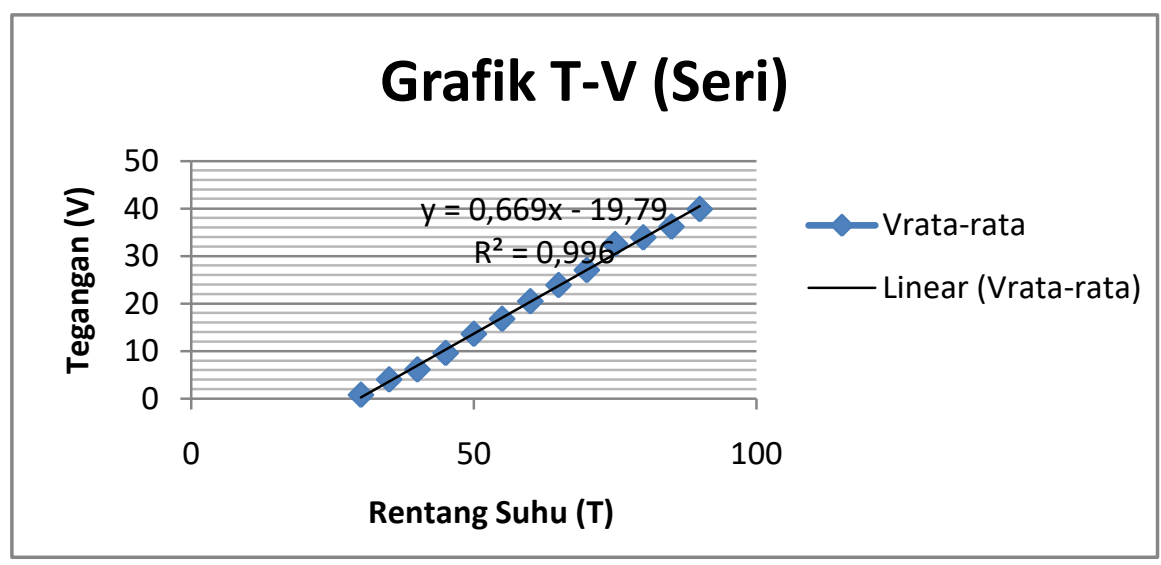

Gambar 7. Grafik hubungan suhu dan tegangan pada pasangan kawat seri.

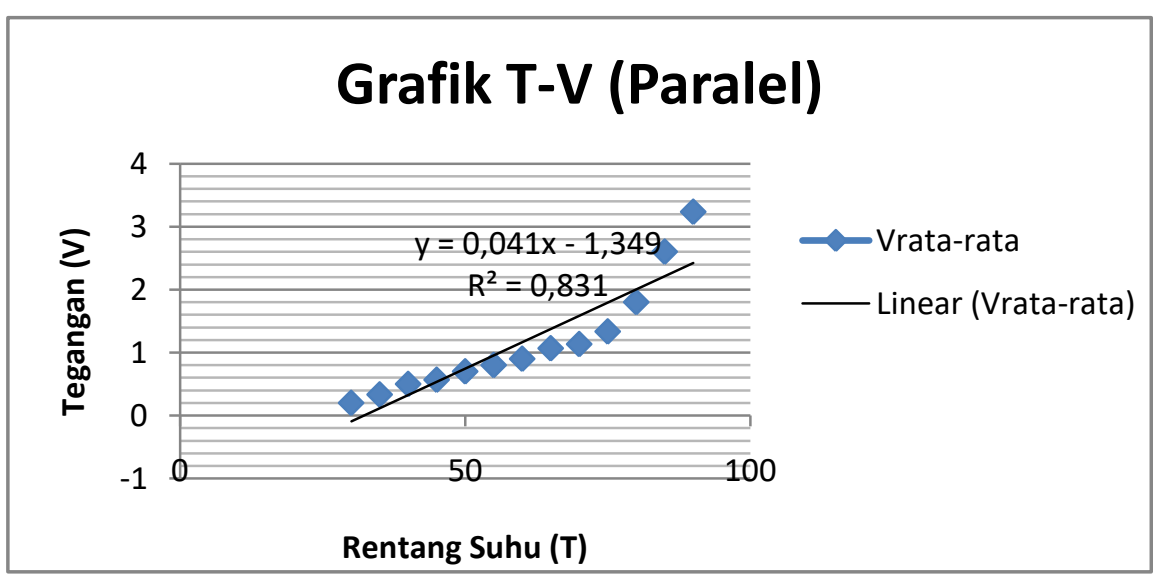

Gambar 8. Grafik hubungan suhu dan tegangan pada pasangan kawat paralel.

Berdasarakan perhitungan peraga, yaitu diperoleh persamaan Y diperoleh nilai koefisien Seebeck $=0,00407 \mathrm{X}+59,99513$ dengan nilai yang menunjukkan sensitivitas alat koefisien Seebeck alat peraga sebesar 
Pratama., Suyanto., Suane. - Peraga Fenomena Kelistrikan...

$0,00407 \mathrm{mV} /{ }^{\circ} \mathrm{C}$ yang artinya terjadi kenaikan tegangan sebesar 0,00407 $\mathrm{mV}$ setiap kenaikan $1^{\circ} \mathrm{C}$ pada pasangan kawat tunggal. Sedangkan pada pasangan kawat yang disusun secara seri diperoleh persamaan $\mathrm{Y}=$ $X+58,68951$ dengan nilai koefisien Seebeck alat peraga sebesar $\mathrm{mV} /{ }^{\circ} \mathrm{C}$ yang artinya terjadi kenaikan tingkat sensitivitas pasangan kawat tembaga dan seng atau kenaikan tegangan sebesar $\mathrm{mV}$ setiap kenaikan $1{ }^{\circ} \mathrm{C}$. Kemudian pada pasangan kawat yang disusun secara paralel diperoleh persamaan $\mathrm{Y}=\mathrm{X}+59,99531$ dengan nilai koefisien Seebeck alat peraga sebesar $\mathrm{mV} /{ }^{\circ} \mathrm{C}$ yang artinya terjadi kenaikan tingkat sensitivitas pasangan tegangan sebesar $\mathrm{mV}$ setiap kenaikan $1{ }^{\circ} \mathrm{C}$.

\section{Pembahasan}

Pada alat peraga fenomena kelistrikan ini terdapat empat besaran fisis yang berperan, diantaranya adalah temperatur, tegangan seebeck, koefisien seebeck dan hambatan dalam.

Berdasarkan data analisis hasil pengukuran dapat diketahui bahwa setiap peningkatan rentang suhu akan menghasilkan peningkatan tegangan listrik. Hasil seperti ditunjukkan pada gambar 7 dan gambar 8 sesuai dengan hasil penelitian dari Wendri, Supardi, Suarbawa, dan Yuliantini, (2012), yang menyatakan bahwa besarnya perubahan suhu dengan tegangan menunjukkan hubungan yang mendekati linier, karena besarnya kenaikan temperatur hampir sama dengan kenaikan tegangan.

Pada rangkaian seri peningkatan jumlah pasangan kawat logam menghasilkan peningkatan tegangan listrik sedangkan hambatan dalamnya cenderung konstan.

Analisis lanjut berdasarkan hasil pengukuran dapat diketahui bahwa: (1) Rata-rata standar deviasi pada pasangan kawat tunggal sebesar 0,058222902 $\mathrm{mV}$ dengan kesalahan relatif sebesar $0,70 \%$; (2) Pada rangkaian kawat seri diperoleh ratarata standar deviasi sebesar 0,37882679 $\mathrm{mV}$ dengan kesalahan relatif sebesar $0,08 \%$; (3) Pada rangkaian kawat paralel diperoleh ratrata standar deviasi sebesar 0,187928345 $\mathrm{mV}$ dengan kesalahan relatif sebesar 0,74\%. Berdasarkan analisis tersebut,maka pemilihan komponen penting dalam 
menghasilkan termolektrik yang baik. Hal ini memperkuat hasil riset dari Riyadi, Suyanto, dan Wahyudi (2015) yang telah mampu menghasilkan prototipe termometer berbasis termoelektrik dengan ketelitian 2,20\%. Namun demikian desain alat yang dikembangkan memiliki sensitivitas $1 \mathrm{mV} / /^{0} \mathrm{C}$ yang lebih rendah dibandingkan dengan desain Rosman (2018) yang memiliki sensitivitas $0,5 \mathrm{mV} /{ }^{0} \mathrm{C}$.

Kelebihan alat peraga fenomena kelistrikan akibat perbedaan temperatur pada pasangan kawat tembaga dan seng diantaranya adalah: (1) Merupakan solusi untuk mengamati perilaku perubahan energi panas menjadi energi listrik; (2) Produk hasil pengembangan dapat digunakan sebagai penuntun belajar bagi siswa secara kelompok, baik dengan menerapkan metode eksperimen atau demonstrasi; dan (3) produk dapat digunakan untuk memberikan pengalaman belajar secara langsung kepada siswa; (4) Mmerupakanvarian baru alat peraga yang bebasis efek seebeck.

Kekurang produk ini diantaranya adalah: (1) Pengukuran membutuhkan es batu, sehingga konverter tidak bisa digunakan secara maksimal di tempat -tempat tertentu yang sulit didapatkan es batu; (2) produk ini menghasilkan energi listrik yang tergolong kecil sehingga proses perubahan energi panas menjadi energi listrik hanya dapat terlihat menggunakan alat ukur digital.

\section{KESIMPULAN DAN SARAN}

\section{Kesimpulan}

Berdasarkan hasil penelitian dan pembahasan, dapat ditarik dua buah kesimpulan. Kesimpulan pertama adalah telah dihasilkan sebuah alat peraga konversi energi panas menjadi energi listrik dengan konsep efek seebeck berbasis lingkungan yang dilengkapi dengan petunjuk penggunaan (user manual). Produk alat peraga fenomena kelistrikan akibat perbedaan temperatur pada pasangan kawat logam yang disertai dengan petunjuk penggunaan, layak digunakan sebagai pelengkap perangkat pembelajaran fisika materi konversi energi panas menjadi energi listrik dengan skor pada uji kelayakan fisik dan skorpada uji ahli desain. 
Pratama., Suyanto., Suane. - Peraga Fenomena Kelistrikan...

Kesimpulan kedua, pada pasangan kawat tembaga dan seng semakin besar nilai maka semakin besar pula tegangan keluaran yang dihasilkan. Peningkatan jumlah kawat yang disusun secara seri menghasilkan peningkatan besar tegangan keluaran. Sedangkan peningkatan jumlah kawat yang disusun secara paralel tidak menunjukkan peningkatan besar tegangan.

\section{Saran}

Saran dari pengembangan ini adalah alat iniakan lebih baik jika diggunakan ditempat yang memiliki intensitas cahaya yang mencukupi. Oleh karena itu, bagi para peneliti selanjutnya perlu mengkombinasikan pasangan elemen yang memungkinkan dapat melakukan pengukuran dengan lebih baik.

\section{DAFTAR PUSTAKA}

Fatonah, S., \& Prasetyo, Z. K. (2014). Pembelajaran sains. Yogyakarta: Penerbit Ombak.

Montecucco, A., Siviter, J., \& Knox, A. R. (2014). The effect of temperature mismatch on thermoelectric generators electrically connected in series and parallel. Applied Energy, 123, 4754.
Pranita, N. H., Azura, K., Ismardi, A., Ajiwiguna, T. A., \& Handayani, I. P. (2015). Implementing Thermoelectric Generator on $C P U$ Processor. eProceedings of Engineering, 2(2).

Prasetyo, Y., Salim, A. T. A., Indarto, B., Sulistiyono., Pangestu, M. A., Habibi, M. R., Cahyanto, M. N., \& Rafi, H. N. (2019). Karakteristik Termoelektrik TEC Bervariasi Tipe Sebagai Pembangkit Listrik DC. Jurnal Energi dan Teknologi Manufaktur (JETM), 2(01), 37-41.

Putra, N., Koestoer, R. A., Adhitya, M., Roekettino, A., \& Trianto, B. (2009). Potensi Pembangkit Daya Termoelektrik untuk Kendaraan Hibrid. Makara Journal of Technology, 13(2).

Ramdini, I. D. (2014). Thermoelectric Generator. Indonesian Jurnal of materials science. 47.

Riyadi, S., Suyanto, E., \& Wahyudi, I. (2015). Prototipe Termometer Berbasis Termoelektrik Untuk Pembelajaran Fisika Materi Suhu dan Kalor. Jurnal Pembelajaran Fisika, 3(6).

Rosman, A. (2018). Perancangan Termokopel Berbahan Besi (Fe) dan Tembaga $(\mathrm{Cu})$ Untuk Sensor Temperatur. Indonesian Journal of Fundamental Sciences, 4(2), 120127.

Sutjahja, M. I. (2010). Penelitian Bahan Termoelektrik Bagi Aplikasi Konversi Energi dimasa Datang. Jurnal Maerial dan Energi Indonesia, 1(1).

Wendri, N., Supardi, I. W., Suarbawa, K. N., \& Yuliantini, N. M. (2012). Alat Pencatat Temperatur 
Pratama., Suyanto., Suane. - Peraga Fenomena Kelistrikan...

Otomatis

Menggunakan

Termokopel

Berbasis

Mikrokontroler AT89S51. Buletin

Fisika, 13(1), 29-33. 